\title{
SRY in an XX male does not influence random chromosome $X$ inactivation: Cytogenetic evidence. Definition of the boundaries of the translocated $Y$ segment through FISH and PCR-RT in a case report and review of the literature
}

\author{
Mariano Stabile $^{1^{*}}$, Vincenzo Altieri ${ }^{2}$, Rosa Salzillo ${ }^{1}$, Panfilo Marrollo ${ }^{1}$, Guglielmo Stabile, \\ Tina Iuorio ${ }^{1}$, Bianca Moscato ${ }^{1}$ \\ 1“"Zigote” Genetic and Prenatal Diagnosis Centre, Salerno, Italy \\ ${ }^{2}$ Genetic Department, Hosp. “Elena d'Aosta”, Naples, Italy \\ ${ }^{3}$ Department of Obstetrics and Gynecology, IRCCS Burlo Garofalo, University of Trieste, Trieste, Italy \\ Email: zigote@tiscalinet.it
}

Received 29 May 2013; revised 13 June 2013; accepted 21 June 2013

Copyright (c) 2013 Mariano Stabile et al. This is an open access article distributed under the Creative Commons Attribution License, which permits unrestricted use, distribution, and reproduction in any medium, provided the original work is properly cited.

\begin{abstract}
We report a case of an SRY positive XX male. The phenotype was completely masculinised except for the reduced facial hair; testes were small, and azoospermia was present. The patient's metaphases, coloured with acridine-orange to reveal the late replicating $X$ chromosome, were sequentially hybridised with SRY and $X$ centromeric probes: a random $X$ chromosome inactivation pattern (XCIP) was present, with SRY present about half the time on both the active $X$ and the inactive $X$. The most likely hypothesis is that the translocated SRY gene escaped inactivation as part of the entire $X$ Pseudo Autosomal telomeric Region 1 (PAR 1). This hypothesis can explain the masculine phenotype, which would be incompatible with a halved expression of SRY. Review of the literature about the association of $46, \mathrm{XX}$ males with a specific XCI pattern is made. The analysis of region $\mathrm{ZZF}$ and QF-PCR for Y polymorphic loci allowed us to define the boundaries of the translocated $Y$ segment as restricted to the region around the SRY locus. Chromosomal fragility analysis, using SCE (Sister Chromatid Exchanges), ruled out chromosomal fragility as a predisposing factor in the proband's father; in addition, no chromosome $Y$ polymorphic variant (inversion, $\mathbf{Y} \mathbf{q h}+/-)$, was present in the proband's father. However, like the AZF region c microdeletions and PRKX/PRKY translocation XX males, a par-
\end{abstract}

"Corresponding author. ticular $Y$ haplotype could be also in this case a predisposing factor.

Keywords: XX Male; SRY; Translocation X-Y;

$X$ Chromosome Inactivation; $Y$ Chromosome

\section{INTRODUCTION}

Two types of XX male are distinguishable from the pathogenetic point of view: XX males with SRY and XX males without SRY. The frequency in the population of Sex Reversal Syndrome (the diagnostic definition of which includes three conditions: hermaphroditism and XX SRY positive and negative males) is 1:20,000 [1]. In XX males without SRY, a mutation occurs in the SOX gene cascade that can cause a gain of function. Instead, in males with SRY, the cause is a translocation between the X chromosome and the $\mathrm{Y}$ chromosome that transfers the SRY gene onto the $\mathrm{X}$ chromosome [2,3]. Normally, the Y chromosome is not able to undergo crossover with the homologous $\mathrm{X}$ chromosome, except for small parts of the PseudoAutosomal telomeric Regions (PAR1 and PAR2) (Ypter ed Yqter) representing about $5 \%$ of the chromosome length [4]. Approximately half of Y genetic loci, which have homologous genes on the $\mathrm{X}$ chromosome, are in PAR regions. The translocation takes place during paternal meiosis. The gene SRY maps to Yp11.31, which is immediately contiguous to the PAR region in pter: the spatial proximity can account for its occasional involvement in a meiotic crossover with a resulting transfer onto 
$\mathrm{X}$. In a few cases of $\mathrm{XX}$ males, SRY is not transferred onto $\mathrm{X}$ but onto an autosome: onto chromosome 3 in the case of Chien [5] and onto chromosome 1 in the case of Queralt [6]. The first case is interesting because it implies two subsequent events: a first event that involved translocation from Yp to Xpter, and a second event that involved translocation from Xpter to 3 pter. The boundaries of the translocated region can be established by analysing the various genetic markers on Yp and Yq. In theory, an SRY gene translocated onto $\mathrm{X}$ could be involved in $\mathrm{X}$ inactivation, even though the telomeric $\mathrm{X}$ pter is preserved from the process. Bouayed Abdelmoula $\mathrm{N}$ et al. [7] have hypothesised that the complete masculinised phenotype in an XX male was related to a preferential inactivation of the $\mathrm{X}$ chromosome that was not rearranged, on the basis of highly skewed X-chromosome inactivation patterns (XCIP) determined by analysis of the methylation status of the androgen receptor gene. Measuring XCI pattern using the methylation assay at the androgen receptor locus in two patients 46, XX, Minor et al. found a random pattern in one patient and non-random in the other [8]. Using the same method, Gunes et al. [9] found a random pattern of XCI in two male patients 46, $\mathrm{XX}$. No random pattern was found instead by Vorona et al. [10] in a XX male. Sharp et al. [11] studied causes of incomplete masculinisation in 15 individuals with segments of Yp traslocated onto distal Xp; expression studies of translocated Y genes by allele specific RT-PCR found very little evidence for spreading of $\mathrm{X}$ inactivation into Yp chromatin. Instead, the above mentioned authors found that translocation carriers with an intersex phenoltype showed either translocation breakpoints very close to SRY, or disrupted expression of genes near SRY in a manner unrelated to $\mathrm{X}$ inactivation. Using the cytogenetic method, here we provide direct cytogenetic evidence that XCIP maintains its random pattern in an XX SRY male, using sequential banding on the same metaphase (orange-acridine banding, which stains the inactive $\mathrm{X}$ chromosome) and subsequent hybridisation with probes for the X centromere and SRY.

The second aim of our report is the definition of the boundaries of the translocated $\mathrm{Y}$ region. FISH confirmed the translocation of SRY onto chromosome $\mathrm{X}$; in addition, the study of DYS393-AMGY markers for the Yp arm and the AZF gene for the Yq arm allowed us to define the limits of the translocated region at a definite level of about $7 \mathrm{Mb}$, which encompasses PAR1 and SRY. Only a few cases in the literature have an exact definition of the translocated region [11,12]. The third contribution of this paper is the investigation into chromosomal fragility as predisposing factor for $\mathrm{X} / \mathrm{Y}$ translocation. Considering the infrequency of SRY positive XX males compared to the hypothetical possibility of an abnormal recombination in the process of $\mathrm{X} / \mathrm{Y}$ crossover which oc- curs during each male meiosis, we have investigated the possible presence of predisposing factors ( $\mathrm{Y}$ inversion, chromosomal fragility) in the father of our proband.

\section{CASE REPORT}

A 35-year-old married man was referred to our centre with a 5 year history of male factor infertility. The proband was the third son of healthy, non-consanguineous couple; his two brothers were fertile with normal children. His height was $173 \mathrm{~cm}$, and his arm span was equal to his height. Apparent masculinisation was complete, except for the reduced facial hair; testes were small $(<10$ $\mathrm{ml}$ ). Azoospermia was present at semen analysis. Hormonal studies revealed hypergonadotropic hypogonadism (LH 35 ml.U./ml, FSH 80 ml.U./ml). He refused a testicular biopsy. Cytogenetic investigation of blood lymphocytes revealed a 46, XX chromosomal constitution in 100 metaphases.

\section{MATERIALS AND METHODS}

\subsection{SRY FISH}

FISH analysis on proband metaphases was performed using SRY and X centromeric probes (Vysis SRY Probe LSI SRY Spectrum Orange/CEP X Spectrum Green ABBOTT MOLECULAR).

\subsection{X-Chromosome Inactivation Patterns (XCIP) Analysis}

We studied "late replicating" X chromosomes on the proband's lymphocyte culture using the BrdU method, which involves the addition of $\mathrm{BrdU}(0.5 \mathrm{mg} / \mathrm{ml}) 7$ hours before stopping the reaction with colchicine; subsequently slides were pre-treated with 33,258 Hoescht colorant ( 5 mg/100 $\mathrm{ml}$ ) for 20 minutes and then were exposed to an Ultraphil sunlamp MLU $300 \mathrm{~W}$ for 20 minutes and coloured with Acridine-Orange ( $5 \mathrm{mg} / 100 \mathrm{ml})$.

\subsection{Chromosomal Fragility Analysis}

To determine the presence of chromosomal fragility, we used the SCE (Sister Chromatid Exchanges) method for lymphocyte cultures of the proband and his father. We performed SCE by adding $0.1 \mathrm{ml}$ BrdU solution (0.5 $\mathrm{mg} / \mathrm{ml}$ ) in $10 \mathrm{ml}$ medium at the beginning of the culture. The slides were treated in the same way as for the examination of late replicating $\mathrm{X}$ chromosomes. Using this method, the tintorial painting of the sister chromatides is different (one pale and the other black), providing evidence of crossovers.

\subsection{Microdeletion Chromosome Y Analysis}

The genomic DNA of the proband was extracted from blood lymphocytes using a commercial kit ("High Pure 
PCR Template Preparation Kit”-Roche-). Amplification was performed through a PCR multiplex reaction; specifically, the following Y-STSs regions were amplified: sY84, sY86 (on region AZFa); sY127, sY134 (on region AZFb); sY254, sY255 (on region AZFc). Amplification products were subsequently revealed through reverse dot blot, (KIT “RhyMA TEST IVF AZF” EUROCLONE). In addition to the $\mathrm{AZFa}, \mathrm{AZFb}, \mathrm{AZF}$ regions, the procedure involves the amplification and revelation of two additional genes: ZFX/ ZFY and SRY (see the Y chromosome map).

\subsection{Quantitative Fluorescent-Polymerase Chain Reaction (QF-PCR)}

Molecular analysis was performed on DNA extracted from the proband's peripherical blood through 4 reactions for the polymorphism analysis (STR) of the Y chromosome (Gen-Probe Elucigene QST*Rplusv2 cat. AN0PLB2). Quantitative fluorescence PCR (QF-PCR) is a Multiplex PCR with fluorescent primers followed by capillary electrophoresis using Beckman CEQ800 Genetic Analysis System. The kit is made by the following markers:

Cr. X: DXS6803, DXS8377, DXS6807, XHPRT; Common X/Y markers: Amelogenin, X22, XY218; Cr. Y: SRY, DYS393, DYS392, DYS288, DYS19, DYS390, DYS389 I-II, DYS385, DYS388, DYS437, DYS438, DYS439

\section{RESULTS}

The FISH analysis of 50 metaphases showed an X chromosome containing the SRY gene (Sex determining Region of the $\mathrm{Y}$ chromosome) at the terminal short arm. This cytogenetic evidence confirms the translocation of a small $\mathrm{Y}$ segment, including the SRY gene, on one $\mathrm{X}$ chromosome (Figure 1). XCIP analysis revealed a pale, inactive $\mathrm{X}$ chromosome in all metaphases. The hybridisation with SRY and X centromeric probes on 50 metaphases, already treated for the evidence of late replicating $\mathrm{X}$ chromosomes, allowed us to establish that the $\mathrm{X}$ translocated chromosome remained active 27/50 and inactive 23/50 (Figure 2), demonstrating that the XCIP random pattern was substantially preserved. Chromosomal fragility analysis using SCE numbers found an average of 6 - 7 SCE for each methaphase, which is not greater than the value found in a population of normal subjects that were not exposed to clastogenic substances [13]. With respect to the Y microdeletion, the deletions mapped to the male specific region on $\mathrm{Y}$ chromosome (MSY), which is localised on Yq and is subdivided into three zones: AZFa, AZFb and AZFc. The AZFc region is the most frequently involved in microdeletions (approximately $80 \%$ ), compared to AZFb (about 9\%) and
AZFa (3\%). The proband's strip is shown in Figure 3. It can be seen all the STS markers are absent, and instead, the ZFX and SRY genes are present. This procedure is not able to distinguish the slight nucleotide difference between the homologous ZFX (Xp22.2 position map) and ZFY (Yp11.3 position map). The human ZFX and ZFY loci have CpG islands near their 5' ends. These islands are typical in that they span approximately $1.5 \mathrm{~kb}$,

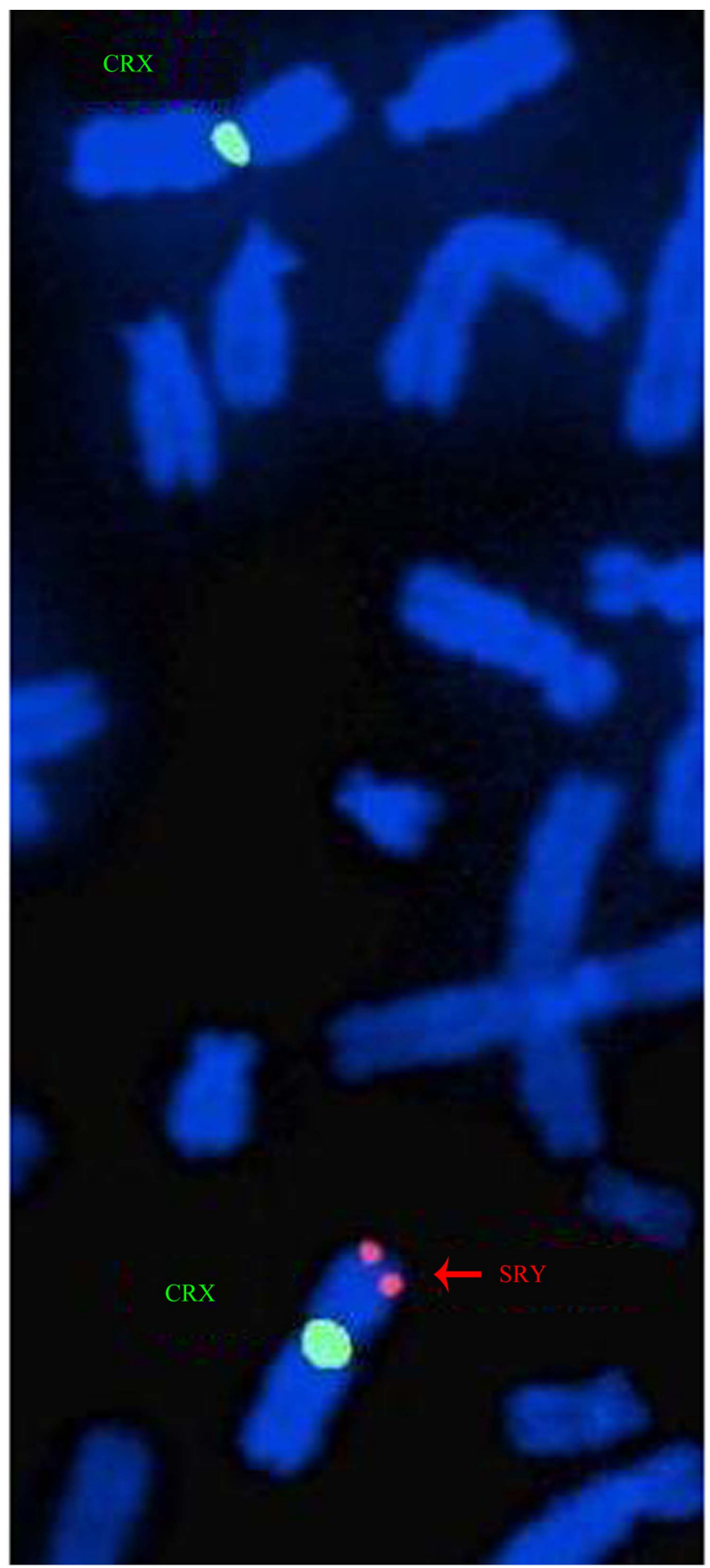

Figure 1. FISH analysis using SRY and $X$ centromeric probes: the double SRY signal on the two chromatides of one $\mathrm{X}$ chromosome. 


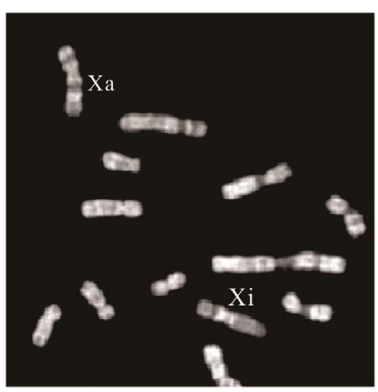

(a)

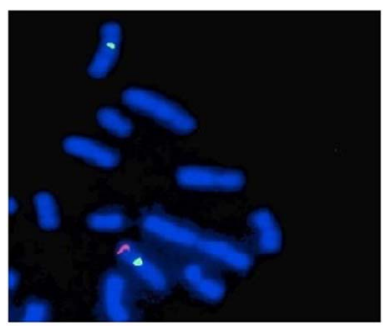

(b)

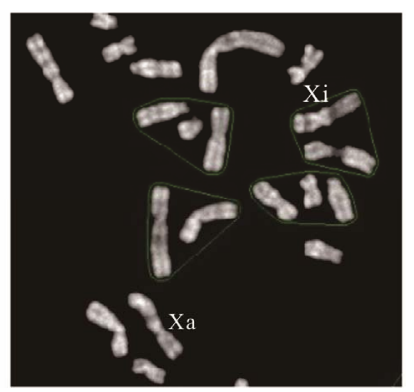

(a1)

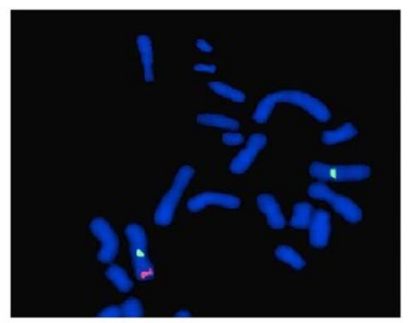

(b1)
Figure 2. (a) Metaphase coloured with acridine-orange; the inactive $\mathrm{X}(\mathrm{Xi})$ is pale compared to the active $\mathrm{X}(\mathrm{Xa})$; (b) The same metaphase after hybridization with SRY and X centromeric probes. The $\mathrm{X}$ with SRY is inactive in the metaphase on the left (a), (b), and it is active in the metaphase on the right.

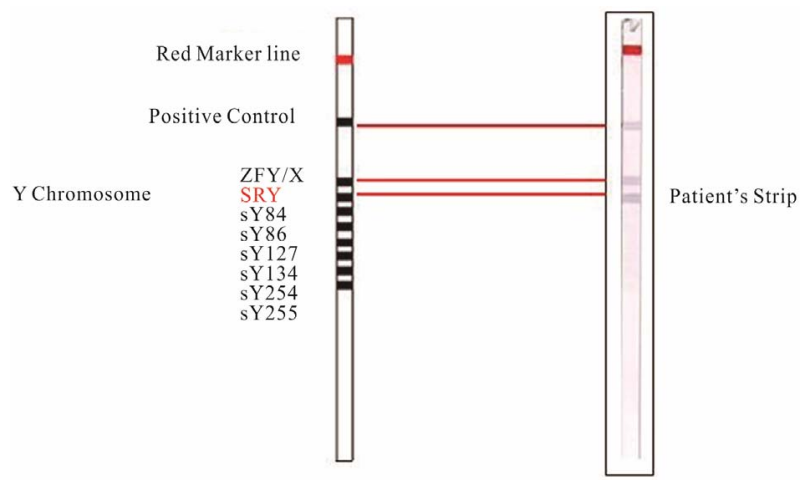

Figure 3. The proband's strip for Y microdeletion: all the STS markers are absent, and instead, the ZFX and SRY genes are present.

contain transcription initiation sites, and encompass some 5' untranslated exons and introns. In one stretch of 165 nucleotides containing 19 CpGs, human ZFX differs from human ZFY at only 9 positions. SchneiderGadicke [14] also showed that ZFX escapes X inactivation in humans. The QF-PCR (Table 1) revealed that only DYS393 and SRY are present in the Y DNA of the patient. DYS393 maps to just at the boundary between PAR1 and SRY [15].

\section{DISCUSSION}

The $\mathrm{Y}$ chromosome can be involved in translocations with all the autosomes; the Y; 15 translocation has been
Table 1. QF-PCR of the proband's Y DNA polymorphic loci: only SRY and DYS393 are present.

\begin{tabular}{ccc}
\hline Chromosome & Locus & Results \\
\hline DYS393 & Present \\
SRY & Present \\
DYS392 & Absent \\
DYS288 & Absent \\
DYS19 & Absent \\
YYS390 & Absent \\
& DYS389 I-II & Absent \\
& DYS385 & Absent \\
DYS388 & Absent \\
DYS437 & Absent \\
DYS438 & Absent \\
DYS439 & Absent \\
\hline
\end{tabular}

found to have an incidence of 5\% in an Ethiopian Community of Ebraic origin [16]. Translocations between chromosomes $\mathrm{X}$ and $\mathrm{Y}$ are less frequent and generally involve Xq [17]. The first meiotic division in males on testicular biopsies appears as a prophase plate with bivalents (paired homologous chromosomes) with crossingover between homologous chromatids; in this phase, chromosomes $\mathrm{X}$ and $\mathrm{Y}$ are located distant from each other or have only one point of connection, at the extremity. X-Y crossing over occurs between the two homologous PAR regions [4]. The male recombination activity in PAR1 is much higher than in the autosomes [18]. Burgoyne [19] proposed that analogous to the autosomes a mechanism exists that ensures at least one chiasma per bivalent in PAR1, and the small size of PAR1 should prevent the formation of more than one chiasma: "Theory of the single obligatory crossover in PAR1”. Because double recombinants have been observed-although very few-in different independent studies, the term "single obligatory" is no longer appropriate. While Y PAR 1 crossover is obligatory, the Y PAR 2 crossover is optional. Using one polymorphic marker in PAR2 and male sex, it has been shown that crossover events in PAR2 are possible and occur in approximately $2 \%$ of male meioses. No recombinants have been observed for PAR2 in women. In PAR2, the male recombination rate is higher than the autosomal average but lower than in PAR1 [20]. The SRY locus maps immediately outside the region PAR1: a crossover with a breakpoint that is a little beyond the boundary of PAR1 has as a consequence the translocation of SRY onto the X chromosome. The precise delimitation of a translocated $\mathrm{Y}$ segment has been performed in this study (Figure 4), and it further confirms that the complete masculinisation of our patient de- 


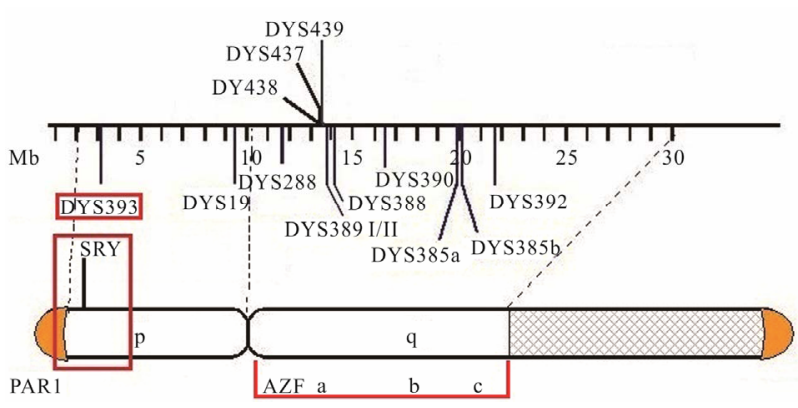

Figure 4. Map of Y with STRs markers, locus SRY and AZF a $\mathrm{b}$ c: the translocated region is delimited in the red box.

pended exclusively on the presence of an active SRY locus in an individual's genome. XCIP analysis revealed random inactivation, likely because the translocation is in the PAR region, which normally escapes inactivation.

However, spermatogenesis requires the AZF locus and other loci on Yq, and therefore it is defective in XX SRY positive males.

Studies on the hypothesis of chromosomal fragility or $\mathrm{Y}$ chromosomal structural variants as predisposing factors for SRY translocation in the proband's father are lacking in the scientific literature. Structural abnormalities include various types of translocations, inversions, deletions, duplications and isochromosomes. Structural abnormalities of the Y chromosome are estimated to affect less than $1 \%$ of the newborn male population and are particularly hazardous for male reproductive function. In the review of Kim JW [21] in 26 men with Y structural variants who consulted a genetic clinic for various reasons, 11 patients had an isodicentric Y chromosome, 7 had an inversion, 3 had a translocation, 2 had a derivative, 2 had a Yqs and 1 had a deletion. Sixteen were diagnosed with azoospermia, 8 were normally fertile and 1 was a man who was unable to donate semen due to mental retardation.

Despite the fact that a large part of the $\mathrm{Y}$ chromosome is spared from genetic recombination deriving from crossovers, some loci, in particular the AZF region, are genetically dynamic regions in the human genome [2224]. In a study of susceptibility to azoospermia factor c microdeletions in a northern Italian population, Arredi et al. [25] found that Y-chromosome haplogroups affect the occurrence of AZFc b2/b4 deletions. Rosser et al. [26] found gene conversion (nonreciprocal transfer of sequence without crossover), frequent among sequences on the malespecific region of the $\mathrm{Y}$ chromosome (MSY) and that the rate of $\mathrm{X}$ to $\mathrm{Y}$ conversion is four to five orders of magnitude more rapid than the rate of Y-chromosomal basesubstitution mutation. Jobling et al. [27] showed that one class of infertile males, PRKX/PRKY translocation XX males, arises predominantly on a particular $\mathrm{Y}$ haplotypic background. In our patient's father, no structural anom- aly of the Y chromosome was present, and chromosomal fragility analysis did not provide evidence of spontaneous fragility or an increase in SCE. However we cannot rule out that a particular Y haplotype could be also in this case a predisposing factor.

\section{REFERENCES}

[1] Wang, T., Liu, J.H., Yang, J., Chen, J. and Ye, Z.Q. (2009) XX male sex reversal syndrome: A case report and review of the genetic basis. Andrologia, 41, 59-62. doi:10.1111/j.1439-0272.2008.00889.x

[2] Heather, P. and Michael, W. (1996) Sox genes: Architects of development. Molecular Medicine, 2, 405-412.

[3] Harley, V.R., Clarkson, M.J. and Argentaro, A. (2003) The molecular action and regulation of the testis-determining factors, SRY (sex-determining region on the $\mathrm{Y}$ chromosome) and SOX9 [SRY-related high-mobility group (HMG) box 9]. Endocrine Reviews, 24, 466-487. doi:10.1210/er.2002-0025

[4] Flaquer, A., Rappold, G.A., Wienker, T.F. and Fischer, C. (2008) The human pseudoautosomal regions: A review for genetic epidemiologists. European Journal of Human Genetics, 16, 771-779. doi:10.1038/ejhg.2008.63

[5] Chien, S.C., Li, Y.C., Ho, M., Hsu, P.C., Teng, R.H., Lin, W.D., Tsai, F.J. and Lin, C.C. (2009) Rare rearrangements: A “jumping satellite” in one family and autosomal location of the SRY gene in an XX male. American Journal of Medical Genetics Part A, 149A, 2775-2781. doi:10.1002/ajmg.a.32958

[6] Queralt, R., Madrigal, I., Vallecillos, M.A., Morales, C., Ballescá, J.L., Oliva, R., Soler, A., Sánchez, A. and Margarit, E. (2008) Atypical XX male with the SRY gene located at the long arm of chromosome 1 and a 1qter microdeletion. American Journal of Medical Genetics Part A, 146A, 1335-1340. doi:10.1002/ajmg.a.32284

[7] Bouayed Abdelmoula, N., Portnoi, M.F., Keskes, L., Recan, D., Bahloul, A., Boudawara, T., Saad, A. and Rebai, T. (2003) Skewed X-chromosome inactivation pattern in SRY positive XX maleness: A case report and review of literature. Annales de Genetique, 46, 11-18. doi:10.1016/S0003-3995(03)00011-X

[8] Minor, A., Mohammed, F., Farouk, A., Hatakeyama, C., Johnson, K., Chow, V. and Ma, S. (2008) Genetic characterization of two 46,XX males without gonadal ambiguities. Journal of Assisted Reproduction and Genetics, 25, 547-552. doi:10.1007/s10815-008-9265-7

[9] Gunes, S., Asci, R., Okten, G., Atac, F., Onat, O.E., Ogur, G., Aydin, O., Ozcelik, T. and Bagci, H. (2013) Two males with SRY-positive 46,XX testicular disorder of sex development. Systems Biology in Reproductive Medicine, 59, 42-47. doi:10.3109/19396368.2012.731624

[10] Vorona, E., Zitzmann, M., Gromoll, J., Schüring, A.N. and Nieschlag, E. (2007) Clinical, endocrinological, and epigenetic features of the 46,XX male syndrome, compared with 47,XXY Klinefelter patients. Journal of Clinical Endocrinology \& Metabolism, 92, 3458-3465. doi:10.1210/jc.2007-0447 
[11] Sharp, A., Kusz, K., Jaruzelska, J., Tapper, W., SzarrasCzapnik, M., Wolski, J. and Jacobs, P. (2005) Variability of sexual phenotype in 46,XX(SRY+) patients: The influence of spreading $X$ inactivation versus position effects. Journal of Medical Genetics, 42, 420-427. doi:10.1136/jmg.2004.022053

[12] Xia, X.Y., Cui, Y.X., Lu, H.Y., Yang, B., Wang, G.H., Pan, L.J., Hou, B.S., Ge, Y.F., Shao, Y., Yao, B. and Huang, Y.F. (2012) Clinical, molecular and cytogenetic studies on 4 patients with 46, XX (SRY positive) male syndrome. Cytogenetic and Genome Research, 136, 270277.

[13] Ben Salah, G., Kamoun, H., Rebai, A., Ben Youssef, A., Ayadi, H., Belghith-Mahfoudh, N., Fourati, A., Ayadi, H. and Fakhfakh, F. (2010) Sister chromatid exchange (SCE) and high-frequency cells (HFC) in peripheral blood lymphocytes of healthy Tunisian smokers. Mutation Research, 719, 1-6. doi:10.1016/j.mrgentox.2010.09.003

[14] Schneider-Gädicke, A., Beer-Romero, P., Brown, L.G., Nussbaum, R. and Page, D.C. (1989) ZFX has a gene structure similar to ZFY, the putative human sex determinant, and escapes X inactivation. Cell, 57, 1247-1258. doi:10.1016/0092-8674(89)90061-5

[15] Hammer, M.F., Chamberlain, V., Kearney, V.F., Stover, D., Zhang, G., Karafet, T., Walsh, B. and Redd, A.J. (2005) Population structure of Y chromosome SNP haplogroups in the United States and forensic implications for constructing Y chromosome STR databases. Forensic Science International.

[16] Chen-Shtoyerman, R., Josefsberg Ben-Yehoshua, S., Nissani, R., Rosensaft, J. and Appelman, Z. (2012) A prevalent $\mathrm{Y} ; 15$ translocation in the Ethiopian Beta Israel community in Israel. Cytogenetic and Genome Research, 136, 171-174. doi:10.1159/000336201

[17] Palka-Bayard-de-Volo, C., De Marco, S., Chiavaroli, V., Alfonsi, M., Calabrese, G., Chiarelli, F. and Mohn, A. (2012) Array-CGH characterization of a de novo $\mathrm{t}(\mathrm{X} ; \mathrm{Y})$ (p22;q11) in a female with short stature and mental retardation. Gene, 504, 107-110. doi:10.1016/j.gene.2012.05.009

[18] Kong, X., Murphy, K., Raj, T., He, C., White, P.S. and Matise, T.C. (2004) A combined linkage-Physical map of the human genome. American Journal of Human Genetics, 75, 1143-1148. doi:10.1086/426405

[19] Burgoyne, P.S. (1982) Genetic homology and crossing over in the $\mathrm{X}$ and $\mathrm{Y}$ chromosomes of Mammals. Human
Genetics, 61, 85-90. doi:10.1007/BF00274192

[20] Freije, D., Helms, C., Watson, M.S. and Donis-Keller, H. (1992) Identification of a second pseudoautosomal region near the Xq and Yq telomeres. Science, 258, 1784-1787. doi:10.1126/science.1465614

[21] Kim, J.W., Park, S.Y., Ryu, H.M., Lee, D.E., Lee, B.Y., Kim, S.Y., Park, Y.S., Lee, H.S. and Seo, J.T. (2010) Molecular and clinical characteristics of 26 cases with structural y chromosome aberrations. Mutation Research, 719, 1-6. doi:10.1016/j.mrgentox.2010.09.003

[22] Navarro-Costa, P., Plancha Carlos, E. and Gonçalves J. (2010) Genetic dissection of the AZF regions of the human Y chromosome: Thriller or filler for male (in)fertility? Journal of Biomedicine and Biotechnology, 2010, 936569. doi:10.1155/2010/936569

[23] Navarro-Costa, P., Gonçalves, J. and Plancha Carlos, E. (2010) The AZFc region of the Y chromosome: At the cross-roads between genetic diversity and male infertility. Human Reproduction Update, 16, 525-542. doi:10.1093/humupd/dmq005

[24] Navarro-Costa, P., Pereira, L., Alves, C., Gusmão, L., Proença, C., Marques-Vidal, P., Rocha, T., Correia, S., Sónia, C.J., Neves, A., Soares Ana, P., Nunes, J., CalhazJorge, Carlos., Amorim, A., Plancha Carlos, E. and Gonçalves, J. (2007) Characterizing partial AZFc deletions of the $\mathrm{Y}$ chromosome with amplicon-specific sequence markers. BMC Genomics, 8, 342. doi:10.1186/1471-2164-8-342

[25] Arredi, B., Ferlin, A., Speltra, E., Bedin, C., Zuccarello, D., Ganz, F., Marchina, E., Stuppia, L., Krausz, C. and Foresta, C. (2007) Y-chromosome haplogroups and susceptibility to azoospermia factor c microdeletion in an Italian population. Journal of Medical Genetics, 44, 205208. doi:10.1136/jmg.2006.046433

[26] Rosser, Z.H., Balaresque, P. and Jobling, M.A. (2009) Gene conversion between the $\mathrm{X}$ chromosome and the male-specific region of the $\mathrm{Y}$ chromosome at a translocation hotspot. American Journal of Human Genetics, 85, 130-134. doi:10.1016/j.ajhg.2009.06.009

[27] Jobling, M.A., Williams, G.A., Schiebel, G.A., Pandya, G.A., McElreavey, G.A., Salas, G.A., Rappold, G.A., Affara, N.A. and Tyler-Smith, C. (1998) A selective difference between human Y-chromosomal DNA haplotypes. Current Biology, 8, 1391-1394. doi:10.1016/S0960-9822(98)00020-7 